\title{
Apigenin suppresses colorectal cancer cell proliferation, migration and invasion via inhibition of the Wnt/ß-catenin signaling pathway
}

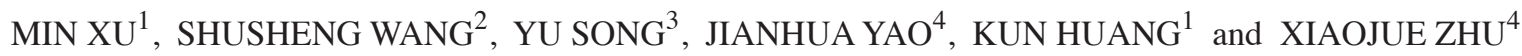 \\ Departments of ${ }^{1}$ Hematology, ${ }^{2}$ Surgery and ${ }^{3}$ Oncology; ${ }^{4}$ Clinical Laboratory, Zhangjiagang Hospital, \\ Suzhou University, Suzhou, Jiangsu 215600, P.R. China
}

Received October 30, 2014; Accepted August 21, 2015

DOI: $10.3892 / \mathrm{ol} .2016 .4331$

\begin{abstract}
Abnormal activation of the Wnt/ $\beta$-catenin signaling pathway has a significant role in human tumorigenesis. The search for potential anticancer drugs has included widespread screening of inhibitors of the Wnt signaling pathway. Recently, one of the most common flavonoids, apigenin, demonstrated potential anti-tumor effects on multiple human cancer cell lines, with low cytotoxicity and no mutagenic activity. However, the association between apigenin and the Wnt/ $/$-catenin signaling pathway remains to be elucidated. The results of wound healing and Transwell invasion assays revealed that apigenin was able to significantly suppress colorectal cancer cell proliferation, migration and invasion in a dose-dependent manner. An organoid culture assay revealed that apigenin was also able to suppress the growth of intestinal organoids. Furthermore, apigenin inhibited $\beta$-catenin/T-cell factor/lymphoid enhancer factor signaling activation, which was induced by $\mathrm{LiCl}$ in a dose-dependent manner. This inhibited $\beta$-catenin nuclear entry, and therefore the expression of Wnt downstream target genes. In conclusion, apigenin significantly suppressed colorectal cancer cell proliferation, migration, invasion and organoid growth by inhibiting the $\mathrm{Wnt} / \beta$-catenin signaling pathway.
\end{abstract}

\section{Introduction}

The Wnt signaling pathway is able to function via two routes: A canonical (Wnt/ $/$-catenin) pathway or a non-canonical Wnt pathway (1). In the canonical Wnt signaling pathway, when

Correspondence to: Dr Xiaojue Zhu, Clinical Laboratory, Zhangjiagang Hospital, Suzhou University, 68 Jiyang West Road, Suzhou, Jiangsu 215600, P.R. China

E-mail: 29317167@qq.com

Dr Shusheng Wang, Department of Surgery, Zhangjiagang Hospital, Suzhou University, 68 Jiyang West Road, Suzhou, Jiangsu 215600, P.R. China

E-mail:wsszyy2005@163.com

Key words: apigenin, Wnt/ $\beta$-catenin signaling pathway, colorectal cancer cell, TOP/FOP flash the Wnt ligand does not bind to its receptors, the pathway is 'switched off'. In this case, $\beta$-catenin is degraded by a destruction complex comprising Axin, adenomatous polyposis coli and glycogen synthase kinase $3 \beta$ (Gsk $3 \beta)$. $\beta$-catenin is phosphorylated in the cytosol, an event which is followed by ubiquitination, resulting in proteasomal degradation (2). When the Wnt pathway is 'switched on', cytosolic $\beta$-catenin is stabilized, resulting in $\beta$-catenin accumulation in the cytoplasm, and subsequent nuclear entry. Once inside the nucleus, $\beta$-catenin activates Wnt target genes by binding to transcription factors of the T-cell factor (TCF)/ lymphoid enhancer factor (LEF) family (3).

Wnt signaling is a crucial mechanism involved in the regulation of cell proliferation, differentiation and morphogenesis (4). Numerous studies have suggested that abnormal activation of the Wnt/ $\beta$-catenin signaling pathway may have a significant role in human tumorigenesis, including in colorectal cancer (CRC), melanoma and lung cancer (5-7). Therefore, the screening of inhibitors of the Wnt signaling pathway is significant in the search for potential anticancer drugs.

Apigenin is one of the most commonly occurring flavonoids, and is found in numerous plants, including parsley, onions, orange, tea, chamomile, wheat sprouts and certain condiments (8). Apigenin has exhibited potential for use in cancer prevention and therapy, and suppresses cell growth in a number of human cancer cell lines, including skin, colon, thyroid, breast, leukemia and prostate cancer cells (9-13). Although previous studies have indicated that the anti-carcinogenic mechanism of apigenin occurs via certain signaling pathways, including the nuclear factor- $\kappa \mathrm{B}, \mathrm{P} 53$ and mitogen activated protein kinase pathways, to the best of our knowledge there have been no previous reports indicating a contributory role of apigenin in the $\mathrm{Wnt} / \beta$-catenin signaling pathway. Therefore, the present study aimed to investigate the effect of apigenin on the migration and invasion of CRC cells, as well as the inhibition of the Wnt/ $\beta$-catenin signaling pathway.

\section{Materials and methods}

Cell lines, cell culture and reagents. Apigenin was purchased from Sigma-Aldrich (St. Louis, MO, USA). A $10 \mathrm{mM}$ solution of apigenin was prepared in sterile water, stored at $-20^{\circ} \mathrm{C}$ and protected from light, and diluted to the required concentrations for each experiment. Human CRC cell lines (SW480 and 
HCT15) were purchased from the American Type Culture Collection (Manassas, VA, USA), cultured and maintained in Dulbecco's modified Eagle's medium (DMEM; HyClone, Logan, UT, USA), supplemented with $10 \%$ heated-inactivated fetal bovine serum (FBS), $100 \mathrm{U} / \mathrm{ml}$ penicillin, $10 \mu \mathrm{g} / \mathrm{ml}$ streptomycin sulfate and then held at $37^{\circ} \mathrm{C}$ in a humidified $5 \% \mathrm{CO}_{2}$ incubator. HEK293T cells were purchased from the Cell Bank of the Chinese Academy of Sciences (Shanghai, China). Mitomycin C was purchased from Roche Diagnostics (Shanghai, China).

Cell viability assay. SW480 and HCT15 human colorectal cancer cells $\left(2 \times 10^{4}\right.$ cells/well) were treated with various concentrations $(0,5,10,20,40$ and $80 \mu \mathrm{M})$ of apigenin for $48 \mathrm{~h}$. Cell viability was determined by MTT assay (Sigma-Aldrich) using a Bio-Rad microplate reader (Model 680; Bio-Rad Laboratories, Inc., Hercules, CA, USA) (14).

Wound healing assay. SW480 cells were cultured to full confluence in 6-well plates and subsequently incubated with $10 \mu \mathrm{g} / \mathrm{ml}$ mitomycin $\mathrm{C}$ for $2 \mathrm{~h}$ to inactivate cell proliferation. Cells were washed with phosphate-buffered saline (PBS) and wounds were made with sterile pipette tips. DMEM supplemented with $0.5 \%$ FBS was added into wells with various concentrations $(0,20$ and $40 \mu \mathrm{M})$ of apigenin. Images of the cells were captured using an Olympus DX41 inverted microscope (Olympus Corp., Tokyo, Japan), following $10 \mathrm{~h}$ of incubation with the aforementioned reagents.

Transwell migration assay. Transwells (Corning Inc., Corning, NY, USA) were coated with $50 \mu 1$ growth factor reduced Matrigel (1:8 dilution; BD Biosciences, Franklin Lakes, NJ, USA) for $30 \mathrm{~min}$ in a cell incubator. The bottom chambers of the Transwells were filled with DMEM containing $0.5 \%$ FBS and the top chambers were seeded with mitomycin $\mathrm{C}$ inactivator, SW480 cells (4x10 4 cells/well) in $100 \mu 1$ DMEM $(0.5 \%$ FBS $)$ and various concentrations $(0,20$ and $40 \mu \mathrm{M})$ of apigenin. Following an overnight incubation, the cells on the top surface of the membrane (non-migrated cells) were removed with a cotton swab and the cells which had migrated onto the bottom sides of the membrane (invasive cells) were then fixed with cold $4 \%$ paraformaldehyde and stained with $2 \%$ crystal violet (Beyotime Institute of Biotechnology, Inc., Shanghai, China). Images were captured using an Olympus DX41 inverted microscope.

Wnt/ $\beta$-catenin signal reporter assay. HEK293T and SW480 cells were plated at a concentration of 5,000 cells/well on white-bottomed 96-well plates. Cells were serum-starved overnight and co-transfected with $0.2 \mu \mathrm{g}$ TOPflash or FOPflash expression plasmids (EMD Millipore, Billerica, MA, USA) and $0.1 \mu \mathrm{g}$ pRL-TK (Renilla TK-luciferase vector; Promega Corp., Madison, WI, USA) as a control, using Lipofectamine ${ }^{\circledR} 2000$ (Invitrogen Life Technologies, Carlsbad, CA, USA). Cells were subsequently treated with $\mathrm{LiCl}(20 \mathrm{mM} / \mathrm{ml})$ for $48 \mathrm{~h}$ prior to the measurement of luciferase activity. Luciferase activity was measured using a Glomax 96 Microplate Luminometer (Turner BioSystems, Sunnyvale, CA, USA). Firefly luciferase activity was normalized for transfection efficiency by dividing the results by the Renilla luciferase activity.
The TOP/FOP ratio was used as a measure of $\beta$-catenin-driven transcription. Average activity and standard deviations were derived from 8 transfected samples.

Reverse transcription-quantitative polymerase chain reaction $(R T-q P C R)$. RNA was extracted using the RNeasy mini kit (Qiagen, Valencia, CA, USA) according to the manufacturer's instructions. Final concentrations were determined using the Nanodrop DA-1000 Spectrophotometer (Thermo Fisher Scientific, Wilmington, DE, USA). RNA (1 $\mu \mathrm{g})$ was purified from genomic DNA using DNase I (Invitrogen Life Technologies) and reverse transcribed to complementary DNA (cDNA) using the QuantiTect W Reverse Transcription kit (Qiagen) according to the manufacturer's instructions. The resulting cDNA product was then used as a template for PCR amplification. A $25 \mu \mathrm{l}$ qPCR reaction mix, consisting of $25 \mathrm{ng}$ diluted cDNA, SYBR Green Dye (Qiagen) and $0.1 \mu \mathrm{M}$ of each qPCR primer pair, was amplified to obtain quantifiable expressions of Wnt downstream genes in SW480 cells. All qPCR was conducted in a Stratagene MxPro ${ }^{\mathrm{TM}}$ 3005P (Agilent Technologies, Inc., Santa Clara, CA, USA). Primer sequences were as follows: Axin2 forward, 5'-CAACACCAGGCGGAACGAA-3' and reverse, 5'-GCCCAATAAGGAGTGTAAGGACT-3'; C-myc forward, 5'-ATGGCCCATTACAAAGCCG-3' and reverse, 5'-TTTCTGGAGTAGCAGCTCCTAA-3'; CylinD1 forward, 5'-GCTGCGAAGTGGAAACCATC-3' and reverse, 5'-ССТССТTCTGCACACATTTGAA-3'; Ephb2 forward, 5'-AGAAACGCTAATGGACTCCACT-3' and reverse, 5'-GTGCGGATCGTGTTCATGTT-3'; Ephb3 forward, 5'-TGGGTAACATCTGAGTTGGCG-3' and reverse, 5'-TGGTATGTGCGGATGGGATTC-3'.

Protein isolation and western blotting. Standard western blotting was performed for protein expression analyses (15). Cells were washed twice with cold PBS and lysed on ice in radioimmunoprecipitation assay buffer containing proteinase inhibitors (Roche Diagnostics). Protein lysates were resolved on $10 \%$ SDS polyacrylamide gel, transferred to nitrocellulose membranes (Beyotime Institute of Biotechnology, Inc.,)and blocked in $0.1 \%$ Tween 20 and $5 \%$ bovine serum albumin (BSA) in Tris-buffered saline. Proteins were probed with rabbit anti- $\beta$-catenin monoclonal antibody (1:1,000; Cell Signaling Technology, Inc., Danvers, MA, USA) and rabbit anti- $\beta$-actin antibody (1:10,000; Sigma-Aldrich) overnight at $4^{\circ} \mathrm{C}$. The membrane was washed and visualized by incubation with horseradish peroxidase-conjugated anti-rabbit IgG polyclonal secondary antibodies for $1 \mathrm{~h}$. Signals were detected by enhanced chemiluminescence (Odyssey, LI-COR Biosciences, Lincoln, NE, USA).

Isolation of intestinal crypts and organoid culture. C57BL/6 mice were purchased from the Laboratory Animal Center (Shanghai, China). An equal number of male $(n=3)$ and female $(n=3)$ mice were kept in specific pathogen-free housing, fed a normal diet and drinking water, and submitted to a 12 -h light/dark cycle and temperatures of $18-23^{\circ} \mathrm{C}$. All animal experiments conformed to the regulations drafted by Association for Assessment and Accreditation of Laboratory Animal Care in Shanghai and were approved by the Ethics Committee of Suzhou University (Suzhou, China). The small 
A<smiles>O=C1CC(c2ccc(O)cc2)Cc2cc(O)cc(O)c21</smiles>

Apigenin $\left(\mathrm{C}_{15} \mathrm{H}_{10} \mathrm{O}_{5}\right)$

Mw: $270.24 \mathrm{~g} / \mathrm{mol}$

B

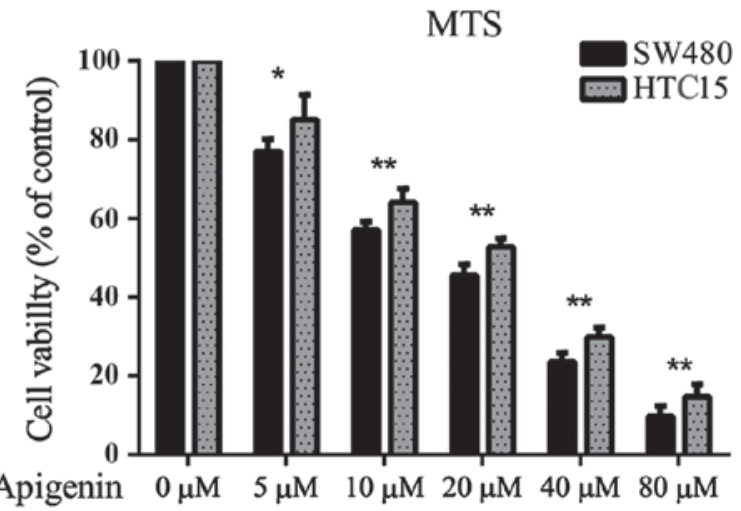

Figure 1. Apigenin inhibits cell viability in SW480 and HCT15 colorectal cancer cells. (A) Chemical structure of apigenin with molecular weight $270.24 \mathrm{~g} / \mathrm{mol}$. (B) Apigenin inhibits SW480 and HCT15 cell viability in a dose-dependent manner. SW480 and HCT15 cells $\left(2 \times 10^{4}\right.$ cells/well) were starved with $0.1 \%$ fetal bovine serum medium and then treated with various concentrations $(0$, $5,10,20,40$ and $80 \mu \mathrm{M})$ of apigenin for $48 \mathrm{~h}$. Cell viability was quantified by MTT assay. Values are expressed as the mean \pm standard error of three independent experiments with six duplicates. ${ }^{*} \mathrm{P}<0.05$ and ${ }^{* * *} \mathrm{P}<0.01$ vs. control.

intestine was separated from mice aged 3-5 weeks following sacrifice by cervical dislocation. After several washes with cold PBS, tissues were divided into $5 \mathrm{~mm}$ sections. Intestinal crypts were selectively isolated as previously described (16); however, certain modifications were made to the subsequent procedures and media in the organoid culture. Briefly, crypts were further dissociated into single cells using Accutase ${ }^{\circledR}$ (Innovative Cell Technologies, Inc., San Diego, CA, USA) treatment for $10 \mathrm{~min}$ at $37^{\circ} \mathrm{C}$ and seeded on polymerized Matrigel (BD Biosciences). Serum-free media optimized for organoid culture containing epidermal growth factor (EGF; Peprotech, Inc., Rocky Hill, NJ, USA), R-Spondin1 (R\&D Systems, Inc., Minneapolis, MN, USA) and Noggin (Peprotech, Inc.) were routinely supplemented with Y27632 (Wako, Osaka, Japan) and Jagged-1 (AnaSpec, Inc., Fremont, CA, USA) to support the survival of single cells and the proliferation of stem cells (14). The medium was replaced every 2 days.

Immunofluorescent staining and confocal microscopy. Cells were fixed using methanol and blocked with 5\% BSA. Cells were subsequently stained with anti- $\beta$-catenin monoclonal antibody (1:1,000, Cell Signaling Technology, Inc.), followed by fluorescein isothiocyanate (FITC)-conjugated goat
A
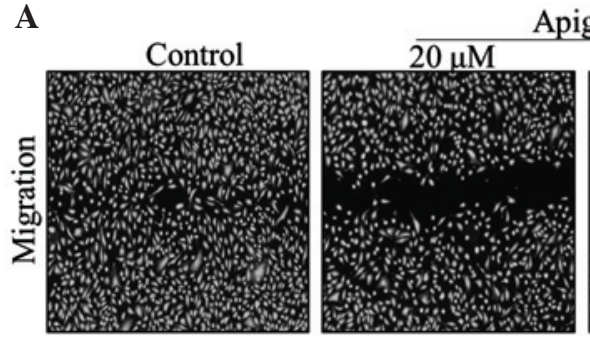

Apigenin
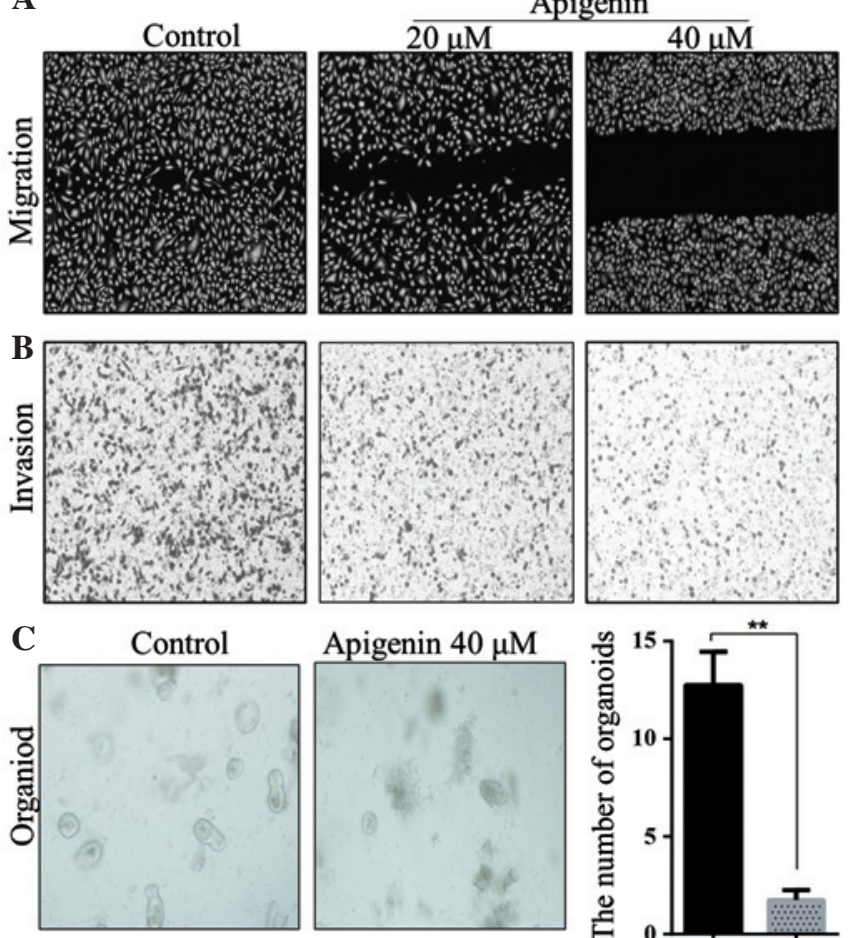

Apigenin $40 \mu \mathrm{M}$
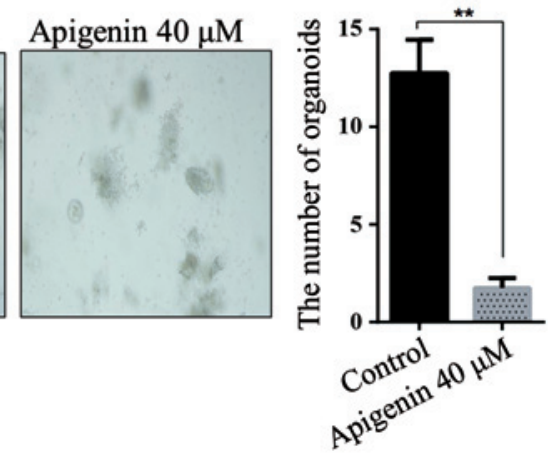

Figure 2. Apigenin inhibits the migration and invasion of SW480 cells, as well as the growth of intestinal organoids. (A) Apigenin inhibited SW480 cellular migration in a dose-dependent manner. SW480 cells were allowed to grow to full confluence in six-well plates, inactivated with $10 \mathrm{ng} / \mathrm{ml}$ mitomycin $\mathrm{C}$ for $2 \mathrm{~h}$, wounded with a pipette tip and treated with or without various concentrations (20 or $40 \mu \mathrm{M})$ of apigenin in medium supplemented with $0.5 \%$ fetal bovine serum. Following incubation, the migrated cells were quantified by manual counting. (B) Apigenin inhibited the invasion of SW480 cells. SW480 were seeded in the upper chamber of a Transwell and treated with various concentrations $(20$ or $40 \mu \mathrm{M})$ of apigenin. (C) Following $\sim 8-10 \mathrm{~h}$, the invasive SW480 cells passed through the membrane and were counted. Values are expressed as the mean \pm standard error of three individual experiments performed in duplicate. ${ }^{* *} \mathrm{P}<0.01$ vs. control. Apigenin inhibited the growth of intestinal organoids at a concentration of $40 \mu \mathrm{M}$ (magnification, x100).

anti-mouse immunoglobulin G (Merck Millipore, Hong Kong, China). Cells were then washed four times with PBS. Nuclear staining was achieved with DAPI. Cells were imaged with a TCS SP2 spectral confocal system (Leica Microsystems $\mathrm{GmbH}$, Wetzlar, Germany). All experiments were conducted according to the antibody manufacturer's instructions.

Statistical analysis. Data are presented as the mean \pm standard error, and statistical comparisons between groups were made using Student's t-test. $\mathrm{P} \leq 0.05$ was considered to indicate a statistically significant difference.

\section{Results}

Apigenin inhibits CRC cell line proliferation. Apigenin is one of the most common flavonoids and has a molecular weight of $270.24 \mathrm{~g} / \mathrm{mol}$ (Fig. 1A). The in vitro anti-proliferative effect of apigenin on the SW480 and HCT15 colorectal cancer cell lines was determined using a standard MTT proliferation 
A

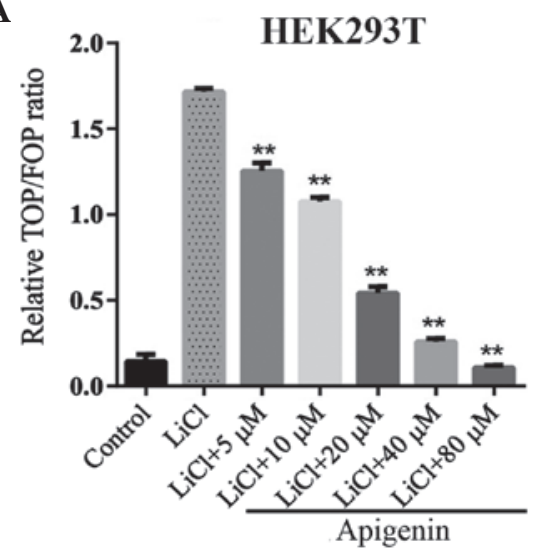

B

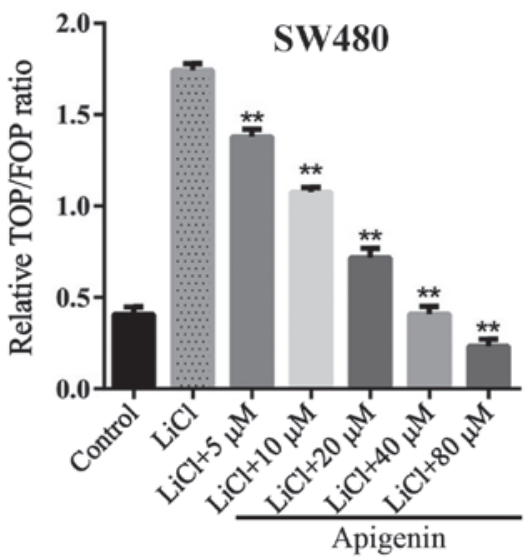

Figure 3. Apigenin inhibits $\beta$-catenin/TCF/LEF signal activation. Stimulation with $\mathrm{LiCl}(20 \mathrm{mM})$ significantly increased the transcription of the Wnt luciferase reporter in (A) HEK293T and (B) SW480 cells. Apigenin significantly inhibited LiCl-induced $\beta$-catenin/TCF/LEF signal activation in a dose-dependent manner. Values are expressed as the mean \pm standard error of three individual experiments performed in duplicate. ${ }^{* *} \mathrm{P}<0.01 \mathrm{vs}$. control.

A

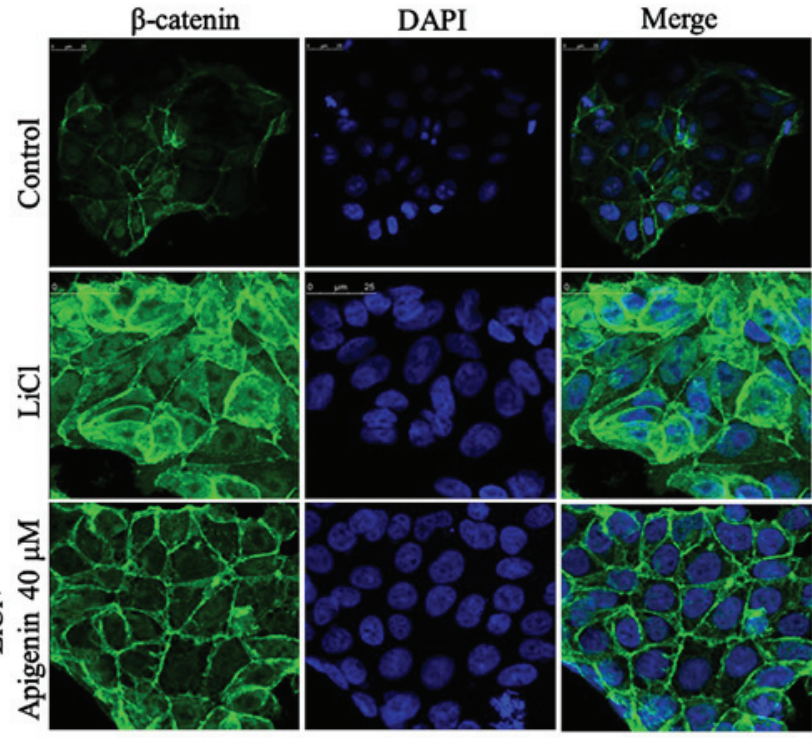

B

C

SW480
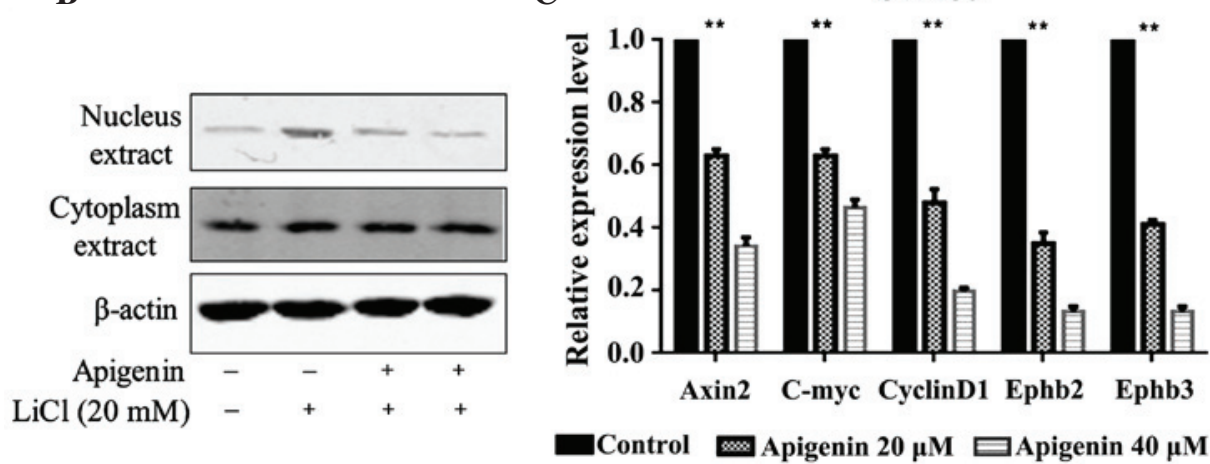

Figure 4. Apigenin inhibits $\beta$-catenin entry into the nucleus and thus the expression of Wnt downstream genes. (A) Apigenin treatment decreased LiCl-activated $\beta$-catenin nuclear entry in the HCT15 colorectal cancer cell line. (B) Apigenin treatment decreased the LiCl-activated expression of $\beta$-catenin in nuclear extracts, but had no effect on the expression in cytosolic extracts of SW480 cells. (C) Apigenin significantly decreased the expression levels of Wnt downstream target genes, including Axin2, C-myc, CylinD1, Ephb2 and Ephb3, in SW480 cells in a dose-dependent manner. Values are expressed as the mean \pm standard error of three individual experiments performed in duplicate. ${ }^{* *} \mathrm{P}<0.01$ vs. control.

assay. The results revealed that apigenin significantly reduced SW480 and HCT15 cell proliferation at an $\mathrm{IC}_{50}$ of $18.17 \mu \mathrm{M}$ and $23.57 \mu \mathrm{M}$, respectively. These data suggest that apigenin may exhibit anti-CRC effects (Fig. 1B). The inhibitive action of apigenin was greater on SW480 cells and therefore these cells were used in subsequent experiments. 
Apigenin inhibits migration and invasion of SW480 cells and growth of intestinal organoids. Tumor migration and invasion are essential steps in tumorigenesis (17). The effects of apigenin on the chemotactic motility of SW480 cells were determined using wound-healing migration and Transwell cell invasion assays. As shown in Fig. 2A and B, apigenin significantly inhibited SW480 cell migration and invasion at 20 and $40 \mu \mathrm{M}$. Furthermore, the inhibition of apigenin on the migration of SW480 cells occurred in a dose-dependent manner. Intestinal organoid culture in vitro requires multiple cytokines, particularly Wnt signaling pathway cytokines. Without Wnt signaling pathway activation, organoids are unable to grow effectively (18). Therefore, $40 \mu \mathrm{M}$ apigenin was added to the intestinal organoid culture system and it was observed that the growth of organoids was significantly inhibited (Fig. 2C).

Apigenin inhibits $\beta$-catenin/TCF/LEF signal activation. The TOPflash/FOPflash luciferase assay is frequently used for the analysis of $\beta$-catenin/TCF/LEF signal activation (19). The TOPflash construct contains two repeats of three optimal copies of the TCF/LEF binding sites, upstream of a thymidine kinase minimal promoter that is able to direct the transcription of the luciferase reporter gene. FOPflash, which contains mutated TCF/LEF binding sites, is used as a negative control (20). The Gsk3 $\beta$ inhibitor $\mathrm{LiCl}$ activates the Wnt pathway; therefore, stimulation with $\mathrm{LiCl}(20 \mathrm{mM})$ significantly increased the transcription of the Wnt luciferase reporter in HEK293T and SW480 cells. Subsequently, the effect of apigenin treatment on HEK293T and SW480 cells and expression of the Wnt luciferase reporter was investigated. Treatment with various concentrations of apigenin and $\mathrm{LiCl}$ (20 mM) inhibited $\beta$-catenin/TCF/LEF signal activation in a dose-dependent manner (Fig. 3A and B).

Apigenin suppresses $\beta$-catenin nuclear entry and the expression of Wnt downstream genes. Wnt signaling activation requires $\beta$-catenin nuclear entry (1). In order to determine how apigenin inhibits the Wnt signaling pathway, immunofluorescent staining was used to examine $\beta$-catenin nuclear entry in HCT15 cells and western blotting was used to examine the expression of $\beta$-catenin in SW480 nuclear and cytoplasmic extracts following $\mathrm{LiCl}$ treatment, as well as treatment with various concentrations of apigenin. Apigenin was found to effectively inhibit LiCl-activated $\beta$-catenin nuclear entry (Fig. 4A) and markedly decrease LiCl-activated expression of $\beta$-catenin in nuclear extracts. However, apigenin had no effect on $\beta$-catenin expression in cytosolic extracts (Fig. 4B). The expression levels of Wnt downstream target genes, including Axin2, C-myc, CylinD1, Ephb2 and Ephb3, were also detected. Apigenin significantly decreased the expression levels of Wnt downstream target genes in a dose-dependent manner (Fig. 4C).

\section{Discussion}

In the United States CRC is the third most common type of cancer, and is second only to lung cancer in terms of mortality, resulting in $\sim 50,000$ mortalities/year (21). Tumorigenesis in sporadic CRC is typically initiated by an inactivating mutation in the APC gene which induces aberrant activation of the Wnt signaling pathway (22). Therefore, inhibition of Wnt signaling may contribute to the treatment of CRC.

Numerous Wnt signaling inhibitors, each of which function at various stages in the Wnt/ $\beta$-catenin pathway, have been reported to be used for the treatment of cancer (23-26). Mesd C-terminal region peptide, similarly to the full-length Mesd protein, was reported to inhibit Wnt 3A- and Rspodin1-induced Wnt/ $\beta$-catenin signaling in LRP5- and LRP6-expressing cells, suppress Wnt/ $\beta$-catenin signaling in HS578T human breast cancer cells and PC-3 prostate cancer cells, and inhibit cancer cell proliferation (27). Calcimycin, a Wnt signaling inhibitor, targets the expression of S100A4 and provides a functional strategy for the restriction of cell motility in colon cancer cells (28). Thus, the results of the present study suggested that apigenin, as a natural compound, may inhibit $\beta$-catenin/TCF/LEF signaling activation, which was induced by $\mathrm{LiCl}$ in a dose-dependent manner, preventing $\beta$-catenin nuclear entry and therefore the expression of $\mathrm{Wnt}$ downstream target genes.

Apigenin has been identified in numerous plants. Recently, it was reported that apigenin may have potential anti-tumor effects on multiple human cancer cell lines with low cytotoxicity and no mutagenic activity $(20,29,30)$. In a study of apigenin as a potential treatment for CRC, apigenin demonstrated inhibition of colorectal cellular migration and invasion. It was shown to suppress the growth of CRC xenografts through decreased phosphorylation of AKT, as well as phosphorylation and upregulation of FADD expression $(31,32)$. In the present study, apigenin significantly suppressed CRC cell proliferation, migration, invasion and intestinal organoid growth.

In conclusion, apigenin significantly suppressed CRC cell proliferation, migration and invasion in a dose-dependent manner. Additionally, apigenin inhibited $\beta$-catenin/TCF/LEF signaling activation, which was induced by $\mathrm{LiCl}$ in a dose-dependent manner. Finally, apigenin inhibited $\beta$-catenin nuclear entry and thereby prevented the expression of Wnt downstream target genes.

\section{Acknowledgements}

The present study was financially supported by a grant from the Open Projects of Jiangsu Provincial Commission of Health and Family Planning (no. 2103).

\section{References}

1. Arend RC,Londoño-Joshi AI, Straughn JM Jr and Buchsbaum DJ: The Wnt/ $\beta$-catenin pathway in ovarian cancer: A review. Gynecol Oncol 131: 772-779, 2013.

2. Noguti J, DE Moura CF, Hossaka TA, Franco M, Oshima CT, Dedivitis RA and Ribeiro DA: The role of canonical WNT signaling pathway in oral carcinogenesis: A comprehensive review. Anticancer Res 32: 873-878, 2012.

3. Pecina-Slaus N: Wnt signal transduction pathway and apoptosis: A review. Cancer Cell Int 10: 22, 2010.

4. Moon RT, Brown JD and Torres M: WNTs modulate cell fate and behavior during vertebrate development. Trends Genet 13: 157-162, 1997.

5. Behrens J: Control of beta-catenin signaling in tumor development. Ann NY Acad Sci 910: 21-35, 2000.

6. Chesire DR, Ewing CM, Sauvageot J, Bova GS and Isaacs WB: Detection and analysis of beta-catenin mutations in prostate cancer. Prostate 45: 323-334, 2000.

7. Polakis P: The oncogenic activation of beta-catenin. Curr Opin Genet Dev 9: 15-21, 1999 
8. Birt DF, Mitchell D, Gold B, Pour P and Pinch HC: Inhibition of ultraviolet light induced skin carcinogenesis in SKH-1 mice by apigenin, a plant flavonoid. Anticancer Res 17: 85-91, 1997.

9. Caltagirone S, Rossi C, Poggi A, Ranelletti FO, Natali PG, Brunetti M, Aiello FB and Piantelli M: Flavonoids apigenin and quercetin inhibit melanoma growth and metastatic potential. Int J Cancer 87: 595-600, 2000.

10. Wang IK, Lin-Shiau SY and Lin JK: Induction of apoptosis by apigenin and related flavonoids through cytochrome $c$ release and activation of caspase- 9 and caspase- 3 in leukaemia HL-60 cells. Eur J Cancer 35: 1517-1525, 1999.

11. Wang W, Heideman L, Chung CS, Pelling JC, Koehler KJ and Birt DF: Cell-cycle arrest at G2/M and growth inhibition by apigenin in human colon carcinoma cell lines. Mol Carcinog 28: 102-110, 2000

12. Yin F, Giuliano AE, Law RE and Van Herle AJ: Apigenin inhibits growth and induces $\mathrm{G} 2 / \mathrm{M}$ arrest by modulating cyclin-CDK regulators and ERK MAP kinase activation in breast carcinoma cells. Anticancer Res 21: 413-420, 2001

13. Zhu Y, Mao Y, Chen H, Lin Y, Hu Z, Wu J, Xu X, Xu X, Qin J and Xie L: Apigenin promotes apoptosis, inhibits invasion and induces cell cycle arrest of T24 human bladder cancer cells Cancer Cell Int 13: 54, 2013

14. Wang YJ, Zhou SM, Xu G and Gao YQ: Interference of Phenylethanoid Glycosides from Cistanche tubulosa with the MTT Assay. Molecules 20: 8060-8071, 2015.

15. Feliciangeli S, Bendahhou S, Sandoz G, Gounon P, Reichold M, Warth R, Lazdunski M, Barhanin J and Lesage F: Does sumoylation control K2P1/TWIK1 background K+ channels? Cell 130: 563-569, 2007.

16. Sato T, Vries RG, Snippert HJ, van de Wetering M, Barker N, Stange DE, van Es JH, Abo A, Kujala P, Peters PJ and Clevers H: Single Lgr5 stem cells build crypt-villus structures in vitro without a mesenchymal niche. Nature 459: 262-265, 2009.

17. Miao L, Xiong X, Lin Y, Cheng Y, Lu J, Zhang J and Cheng N: MiR-203 inhibits tumor cell migration and invasion via caveolin-1 in pancreatic cancer cells. Oncol Lett 7: 658-662, 2014.

18. Schuijers J, Junker JP, Mokry M, Hatzis P, Koo BK, Sasselli V, van der Flier LG, Cuppen E, van Oudenaarden A and Clevers H: $\mathrm{Ascl} 2$ acts as an R-spondin/Wnt-responsive switch to control stemness in intestinal crypts. Cell stem cell 16: 158-170, 2015.

19. Osada T, Chen M, Yang XY, Spasojevic I, Vandeusen JB, Hsu D Clary BM, Clay TM, Chen W, Morse MA and Lyerly HK: Antihelminth compound niclosamide downregulates Wnt signaling and elicits antitumor responses in tumors with activating APC mutations. Cancer Res 71: 4172-4182, 2011.

20. Shen $X$, Ying $H$ and Yue BY: Wnt activation by wild type and mutant myocilin in cultured human trabecular meshwork cells. PLoS One 7: e44902, 2012

21. Haggar FA and Boushey RP: Colorectal cancer epidemiology: Incidence, mortality, survival and risk factors. Clin Colon Rectal Surg 22: 191-197, 2009.
22. Blair V, Kahokehr A and Sammour T: Cancer in Māori: Lesson from prostate, colorectal and gastric cancer and progress in hereditary stomach cancer in New Zealand. ANZ J Surg 83: 42-48, 2013.

23. Lazarova DL, Chiaro C, Wong T, Drago E, Rainey A, O'Malley S and Bordonaro M: CBP Activity Mediates Effects of the histone deacetylase inhibitor butyrate on WNT activity and apoptosis in colon cancer cells. J Cancer 4: 481-490, 2013.

24. Chong KY, Hsu CJ, Hung TH, Hu HS, Huang TT, Wang TH, Wang C, Chen CM, Choo KB and Tseng CP: Wnt pathway activation and $\mathrm{ABCB} 1$ expression account for attenuation of proteasome inhibitor-mediated apoptosis in multidrug-resistant cancer cells. Cancer Biol Ther 16: 149-159, 2015.

25. Jang GB, Hong IS, Kim RJ, Lee SY, Park SJ, Lee ES, Park JH, Yun CH, Chung JU, Lee KJ, et al: Wnt/beta-catenin small-molecule inhibitor CWP232228 preferentially inhibits the growth of breast cancer stem-like cells. Cancer Res 75: 1691-1702, 2015.

26. Hall CL, Zhang H, Baile S, Ljungman M, Kuhstoss S and Keller ET: p21CIP-1/WAF-1 induction is required to inhibit prostate cancer growth elicited by deficient expression of the Wnt inhibitor Dickkopf-1. Cancer research 70: 9916-9926, 2010.

27. Lin C, Lu W, Zhang W, Londoño-Joshi AI, Buchsbaum DJ, Bu G and $\mathrm{Li} Y$ : The C-terminal region Mesd peptide mimics full-length Mesd and acts as an inhibitor of Wnt/ $\beta$-catenin signaling in cancer cells. PLoS One 8: e58102, 2013.

28. Sack U, Walther W, Scudiero D, Selby M, Aumann J, Lemos C, Fichtner I, Schlag PM, Shoemaker RH and Stein U: S100A4-induced cell motility and metastasis is restricted by the Wnt/ $\beta$-catenin pathway inhibitor calcimycin in colon cancer cells. Mol Biol Cell 22: 3344-3354, 2011.

29. Seo HS, Ku JM, Choi HS, Woo JK, Jang BH, Shin YC and Ko SG: Induction of caspase-dependent apoptosis by apigenin by inhibiting STAT3 signaling in HER2-overexpressing MDA-MB-453 breast cancer cells. Anticancer Res 34: 2869-2882, 2014

30. Wu DG, Yu P, Li JW, Jiang P, Sun J, Wang HZ, Zhang LD, Wen MB and Bie P: Apigenin potentiates the growth inhibitory effects by IKK- $\beta$-mediated NF- $\mathrm{B}$ activation in pancreatic cancer cells. Toxicol Lett 224: 157-164, 2014.

31. Chunhua L, Donglan L, Xiuqiong F, Lihua Z, Qin F, Yawei L, Liang Z, Ge W, Linlin J, Ping Z, et al: Apigenin up-regulates transgelin and inhibits invasion and migration of colorectal cancer through decreased phosphorylation of AKT. J Nutr Biochem 24: 1766-1775, 2013.

32. Wang QR, Yao XQ, Wen G, Fan Q, Li YJ, Fu XQ, Li CK and Sun XG: Apigenin suppresses the growth of colorectal cancer xenografts via phosphorylation and up-regulated FADD expression. Oncol Lett 2: 43-47, 2011. 